\title{
Effects of the Muscle Energy Technique and the Self-Stretching Exercise of the Pectoralis Minor on the Pulmonary Function of Young Adults with Thoracic Kyphosis
}

\author{
Jae-woo Park, BSc; Sung-dae Choung, PT, Ph.D \\ Department of Physical Therapy, Baekseok University, Cheon-an, South Korea
}

Background Thoracic kyphosis leads to the narrowing of the rib cage, compression of the lungs, and reduced mobility, resulting in decreased expansion of the lungs.

Purpose This study investigates the effects of the muscle energy technique and the self-stretching exercise of the pectoralis minor muscle on the pulmonary function of young subjects with kyphosis.

Study design Design Pre-test post-test control group design.

Methods Thoracic kyphosis was determined by adding the angle of the seventh cervical vertebra and the first thoracic vertebra and the angle of the twelfth thoracic vertebra and the first lumbar vertebra. Excessive kyphosis was defined as a curvature measuring more than $40^{\circ}$. For the respiratory function, forced vital capacity (FVC), one-second forced expiratory volume (FEV1), and peak expiratory flow rate were measured using a Pony FX. Then, six sets of the muscle energy technique and the self-stretching exercise were performed, with three sets each for the left and right sides of the body. Each set consisted of 10 repetitions of a $10 \mathrm{~s}$ exercise, and $30 \mathrm{~s}$ breaks were given between sets.

Results Results showed that the self-stretching exercise reduced the thoracic kyphosis and significantly increased the FVC and FEV1. The muscle energy technique reduced the kyphosis and significantly increased the FVC.

Conclusions The two intervention methods, the muscle energy technique and the self-stretching exercise, can be applied as effective treatment programs to improve the pulmonary function of subjects with thoracic kyphosis.

Key words Kyphosis; Muscle energy technique; Pulmonary function; Pectoralis minor; Selfstretching.

\section{INTRODUCTION}

The thoracic spine consists of 12 vertebral segments located between the neck and the lumbar spine, and it is composed of a rigid structure connected to the ribs. The spine has a stable structure with a complex ligament, such as a radiant ligament attached to the vertebral body, intervertebral discs and ribs, and strong intercostal fascia. ${ }^{1}$

Physiological movements of the spine are caused by coupled motions occurring in the intervertebral joints and rib
JMST

2020; 4(1): 6-12

Published Online Jun 30,2020

pISSN 2635-8573 eISSN 2635-8581

Article History

Received 28 Apr 2020 Revised 15 May 2020 (1st)

Revised 26 May 2020

(2nd)

Accepted 27 May 2020

\section{CONTACT}

dae282282@bu.ac.kr

Sung-dae Choung,

Department of Physical

Therapy, Baekseok

University, Cheon-an,

South Korea

This is an Open-Access article distributed under the terms of the Creative Commons Attribution Non-Commercial L cense (http://creativecommons. org/licenses/by-nc/4.0) which permits unrestricted non-commercial use, distribution, and reproduction in any medium, provided the original work is properly cited. 
the trunk muscles is broken. The weakening of the hair roots may be the cause. ${ }^{7}$ This increased spine curvature adds to the load on the spine, which contributes to pain and disability, resulting in severe stress to the bones, joints, ligaments, and muscles. Tension occurs, causing muscle weakness and stretching support for the spine. ${ }^{8}$ A previous study confirmed the reduction of thoracic kyphosis by applying renal and muscle strengthening exercises to the individual with thoracic kyphosis. ${ }^{9}$

Deformity of the spine leads to the narrowing of the rib cage due to growth disorders, compression of the lungs, and reduced mobility, resulting in decreased swelling and contraction of the lungs and thus in reduced muscle activity in the chest and weakening of the respiratory muscles. ${ }^{10}$ A small deformation of the spine does not significantly affect the cardiopulmonary function, but as the deformation gradually increases, cardiopulmonary function disorder occurs. ${ }^{6,11}$

Research on the cardiopulmonary function of patients with spinal curvature is still insufficient. Thus, this study investigated the changes in spine bends and respiratory function when the self-extension exercise and the muscle energy technique of trunk muscles are applied to individuals with thoracic kyphosis of over $40^{\circ}$.

\section{METHODS}

\section{Subjects}

This study selected 30 subjects ( 24 males and 6 females) who fully understood the purpose of the study among college students attending Baekseok University in Cheonan and who agreed to participate in the study. The selection criterion for the study subjects was individuals with thoracic kyphosis of $40^{\circ}$ or more, ${ }^{12}$ and the exclusion criteria were those who did not experience spinal surgical treatment, those without rheumatoid disease and arthritis, and the respiratory system. Those with no disease, no neurological diseases, and no other diseases that could affect the experiment were selected.

\section{Study procedure}

\section{1) Thoracic kyphosis measurement}

The subject faced the front and walked in place for $10 \mathrm{~s}$. Then, the subject stood in a comfortable position with the feet spread over the shoulder width. ${ }^{13}$ A previous study reported that the method of combining the bubble inclinometer and observation to confirm thoracic kyphosis could show the correct posture. ${ }^{14}$ The areas of the seventh cervical vertebra and the first lumbar vertebra were found and marked. The lowest rib in the right position was found to determine the first lumbar vertebra, and then the twelfth vertebra and the first lumbar vertebra were shown. The positions of the twelfth thoracic vertebra and the first thoracic vertebra were indicated by attaching markers.

To use the inclinometer, the subject stood in a comfortable position with eyes staring in front, resting the arm and fixing the posture. The angle of inclination of the seventh cervical vertebra and the first vertebra shown through observation was measured using an angle gauge, followed by that of the twelfth vertebra and the first lumbar vertebra. ${ }^{6}$ The total measurement was performed three times, and the average value was used as the final value (Figure 1). Inclinometers are easy to use and have reduced potential errors in measurement. ${ }^{15}$

\section{2) Respiratory function measurement}

The respiratory function of the subjects was measured using a respiratory function meter (Pony FX, Cosmed Inc., Korea) (Figure 2). The Pony FX used to measure respiratory function has been reported to have a very high confidence level of $0.99 .{ }^{16}$ The measurement indicators measured the forced vital capacity (FVC), forced expiratory volume in 1 second (FEV1), and peak expiratory flow. Effortful waste is an indicator of the total exhaled volume from one breath during maximum exhalation. The expiratory volume per second is the index indicating the expiratory volume discharged during the first $1 \mathrm{~s}$ of the maximum expiratory expiration. ${ }^{17}$ These measurement indicators are the basic measurements in evaluating respiratory function, and the measured values may be measured differently depending on the posture of the experimenter. In general, the lying down

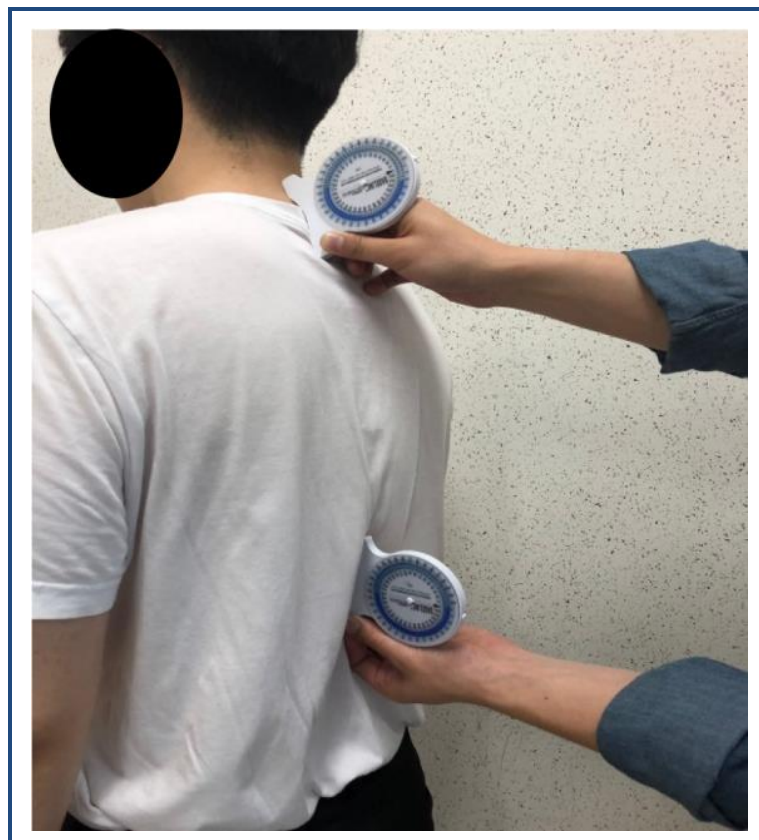

Figure 1. Measurement of thoracic kyphosis. 

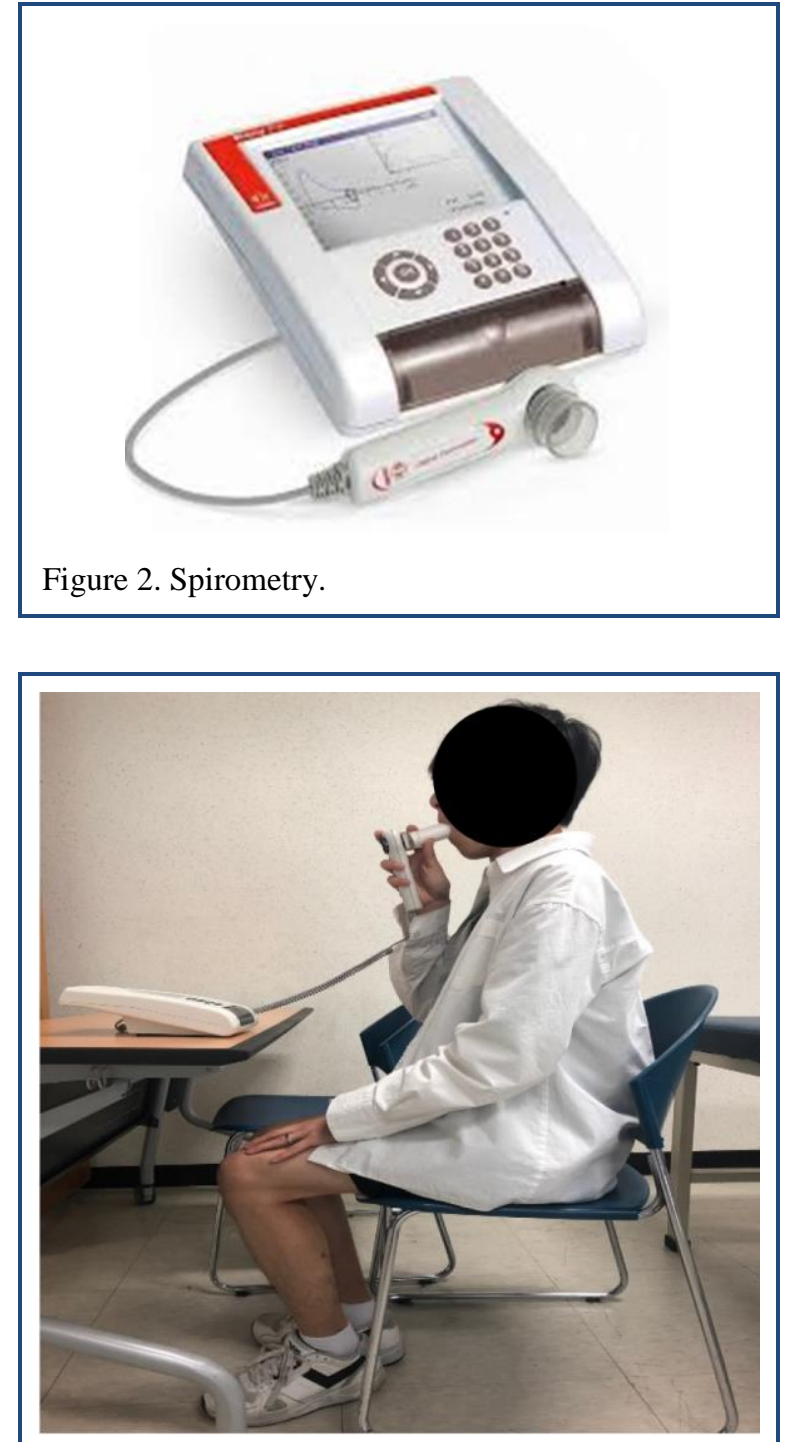

Figure 3. Measurement of pulmonary function.

posture in a normal person is measured to have a lower pulmonary function than the sitting posture. The reason is that in the lying position, the measured value may be low because the organs or muscles of the abdomen press against the diaphragm. ${ }^{18}$ Therefore, in this study, the hip and knee joints were bent at $90^{\circ}$, and the waist and chest were positioned in a straight posture to accurately measure respiratory function. In the measurement, each index was measured three times, and the average value was used as the final value.

\section{Intervention}

\section{1) Control group}

The control group was allowed to sit back and rest with the knee and hip joints bent at $90^{\circ}$ for $12 \mathrm{~min}$, which is the same as the intervention time in the other two groups. Before and after resting, the degree of spine bending and respiratory function were measured.

\section{2) Self-stretching group}

In the self-extension exercise group, before starting the exercise, training was conducted on the exercise programs, and the exercises were learned through a direct motion demonstration. The subject stood shoulder-to-wall, with the shoulders bent at a $90^{\circ}$ angle and the palms facing the wall (Figure 4). In this position, one step forward was made, and stretching was performed by stretching the small pectoral muscle on the wall. ${ }^{19}$ The exercise was maintained for $10 \mathrm{~s}$ in both left and right movements and repeated 10 times. Three sets were performed, and the resting time between each set was $30 \mathrm{~s}$.

\section{3) Muscle energy technique group}

The group of muscle energy techniques underwent training on the exercise programs before starting the exercise, and the subjects learned the exercise through a direct movement demonstration. The subject lies on the treatment table, with both feet together and both knees bent. The researcher tries to press the subject's scapular down the treatment table, while the subject resists it. The position is held for $10 \mathrm{~s}$, and relaxation is repeated (Figure 5). ${ }^{20}$ The exercise was maintained for $10 \mathrm{~s}$ in both left and right movements and repeated 10 times. Three sets were performed, and the resting time between each set was $30 \mathrm{~s}$.

\section{Statistical analysis}

To compare the difference between thoracic kyphosis in

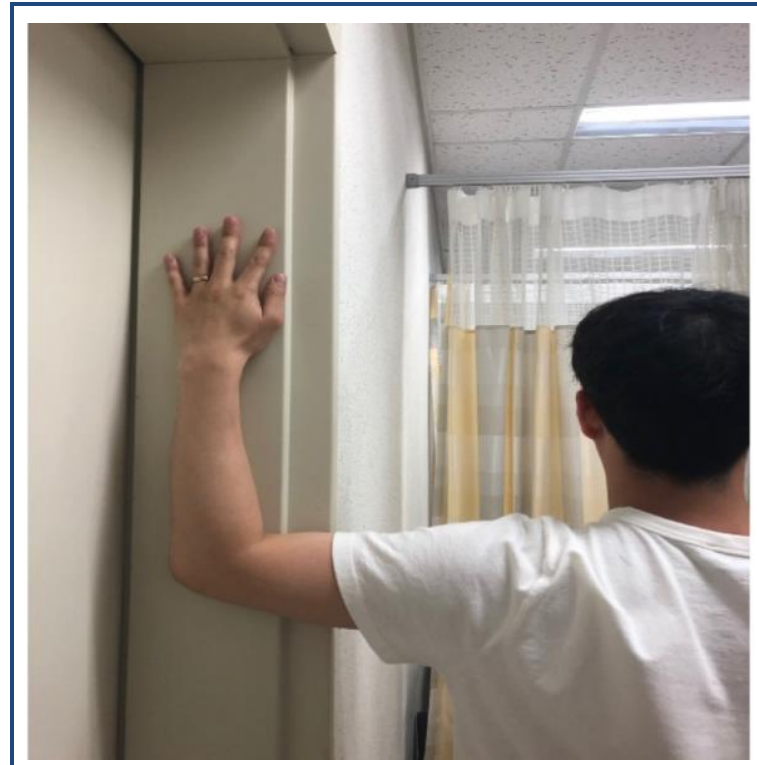

Figure 4. Self-stretching posture. 


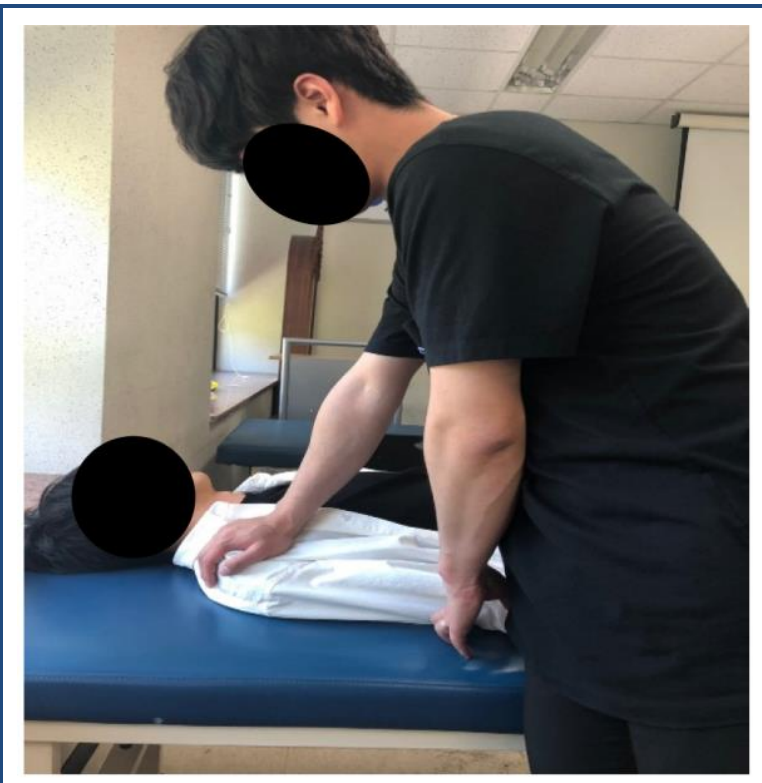

Figure 5. Muscle energy technique posture.

the group and the respiratory function according to each intervention technique, a paired $t$-test of the SPSS ver. 20 program was used. One-way ANOVA and post-analysis Scheffe test were used to compare the changes in bending and respiratory function. The statistical significance level was set to 0.05 .

\section{RESULTS}

The differences in thoracic kyphosis and the respiratory function of the subjects in each group according to each intervention technique were compared. In the control group, no significant differences were found in kyphosis angle, effortful aeration, $1 \mathrm{~s}$ effortful expiratory volume, and maximum expiratory speed (Table 1). In the self-extension exercise group, thoracic kyphosis significantly decreased, but it significantly increased in the effortful waste amount and effortful expiratory amount in $1 \mathrm{~s}$ (Table 2). In the group of muscle energy technique, thoracic kyphosis significantly decreased, but it significantly increased in effortful waste (Table 3).

We compared the thoracic kyphosis and respiratory function between the groups according to the three intervention techniques (Table 4). Kyphosis angle significantly decreased in the self-stretching exercise group compared with the control group, but it significantly increased in the effortful waste amount and effortful exhalation amount in $1 \mathrm{~s}$ [Table 4]. Spine curvature was significantly decreased in the muscle energy technique group compared with the control group, but it significantly increased in effortful waste (Table 4). The $1 \mathrm{~s}$ effortful expiratory volume increased more in the selfextension exercise group than in the muscle energy technique group. The maximum exhalation speed slightly increased in the muscle energy technique group compared with the selfextension exercise group.

\section{DISCUSSION}

Most lesions are caused by the lack of exercise, persistent stress, and incorrect posture. ${ }^{21}$ The spine, which transmits

Table 1. Comparison of pulmonary function and kyphosis angle in pre-test and post-test of control group

$(\mathrm{N}=10)$

\begin{tabular}{cccccc}
\hline & & Pre test & Post test & $t$ value & $p$ value \\
\hline \multirow{2}{*}{$\begin{array}{c}\text { Pulmonary } \\
\text { function }(\%)\end{array}$} & FVC $(\mathrm{L})$ & $4.34 \pm 1.13$ & $4.19 \pm 1.07$ & 2.74 & 0.02 \\
& FEV1 $(\mathrm{L} / \mathrm{sec})$ & $3.49 \pm 0.64$ & $3.49 \pm 0.65$ & -0.30 & 0.77 \\
& PEF(L/sec) & $5.62 \pm 0.92$ & $5.67 \pm 1.16$ & -0.027 & 0.80 \\
& Kyphosis $(\mathrm{deg})$ & $43.50 \pm 0.97$ & $43.40 \pm 0.95$ & 0.29 & 0.78 \\
\hline
\end{tabular}

Data are expressed as mean \pm SD. FVC, forced vital capacity; FEV1, forced expiratory volume in 1sec; PEF, peak expiratory flow; * $p<0.05$.

Table 2. Comparison of pulmonary function and kyphosis angle in pre-test and post-test of self-stretching group $\quad(\mathrm{N}=10)$

\begin{tabular}{cccccc}
\hline & & Pre test & Post test & $t$ value & $p$ value \\
\hline \multirow{2}{*}{$\begin{array}{c}\text { Pulmonary } \\
\text { function (\%) }\end{array}$} & FEV (L) & $3.97 \pm 0.79$ & $4.09 \pm 0.78$ & -7.22 & $<0.01^{*}$ \\
& FEV1 (L/sec) & $3.69 \pm 0.62$ & $3.77 \pm 0.62$ & -2.57 & 0.03 \\
\multicolumn{2}{c}{ Kyphosis (deg) } & $5.05 \pm 1.12$ & $5.14 \pm 1.19$ & -1.89 & 0.09 \\
\hline
\end{tabular}

Data are expressed as mean \pm SD. FVC, forced vital capacity; FEV1, forced expiratory volume in 1sec; PEF, peak expiratory flow; ${ }^{*} p<0.05$. 
Table 3. Comparison of pulmonary function and kyphosis angle in pre-test and post-test of muscle energy technique group

$(\mathrm{N}=10)$

\begin{tabular}{cccccc}
\hline & & Pre test & Post test & $t$ value & $p$ value \\
\hline & FVC (L) & $4.49 \pm 0.62$ & $4.70 \pm 0.68$ & -4.67 & $0.01^{*}$ \\
$\begin{array}{c}\text { Pulmonary } \\
\text { function (\%) }\end{array}$ & FEV1 (L/sec) & $4.24 \pm 0.53$ & $4.47 \pm 0.55$ & -6.44 & $0.01^{*}$ \\
\multicolumn{2}{c}{ Kyphosis (deg) } & $4.81 \pm 1.25$ & $4.94 \pm 1.30$ & -0.81 & 0.44 \\
\hline
\end{tabular}

Data are expressed as mean \pm SD. FVC, forced vital capacity; FEV1, forced expiratory volume in 1sec; PEF, peak expiratory flow; ${ }^{*} p<0.05$.

Table 4. Comparison of pre-test and post-test differences between the three groups

$(\mathrm{N}=30)$

\begin{tabular}{ccccccc}
\hline & & CG & SSG & METG & $F$ value & $p$ value \\
\hline & FEV(L) & $-.15 \pm .18$ & $.21 \pm .15$ & $.12 \pm .052$ & 19.85 & $<0.01^{*}$ \\
$\begin{array}{c}\text { Pulmonary } \\
\text { function (\%) }\end{array}$ & FEV1 (L/sec) & $.01 \pm .07$ & $.22 \pm .11$ & $.08 \pm .098$ & 13.93 & $<0.01^{*}$ \\
& PEF (L/sec) & $.45 \pm .53$ & $.13 \pm .52$ & $.08 \pm .42$ & 0.10 & 0.90 \\
Kyphosis (deg) & & $-.10 \pm 1.1$ & $-9.50 \pm 2.76$ & $-9.70 \pm 5.89$ & 20.75 & $<0.01^{*}$ \\
\hline
\end{tabular}

Data are expressed as mean \pm SD. CG, control group; SSG, self-energy group; METG, muscle energy technique group; FVC; forced vital capacity; FEV1, forced expiratory volume in 1sec; PEF, peak expiratory flow; ${ }^{*} p<0.05$.

forces between the upper and lower body of an individual, is an important segment that requires stability and mobility for optimal function. ${ }^{22,23}$ In humans, an increased spine curvature is considered to be caused by structural changes and poor habits, and anatomical changes and decreased mobility significantly increase spine curvature. ${ }^{4,24}$ When thoracic kyphosis increases, it causes many problems, such as changes in the musculoskeletal system, functional limitations of the body, falls, and increased mortality. ${ }^{6}$ In changes in the musculoskeletal system, as the mobility of joints decreases, stress is applied to other joints because of compensatory effects, and the functional limitations of the upper and lower extremities cause negative effects on daily activities or life. ${ }^{25,26}$ Moreover, excessive spinal curvature decreases respiratory function and increases mortality due to cardiopulmonary problems. ${ }^{27,28}$ Recently, the importance of the effects of active exercise on patients with thoracic kyphosis has been demonstrated. ${ }^{29,30}$

This study aimed to investigate the effects of selfextension and muscle energy techniques on kyphosis angle and respiratory function. The results showed that spine bending significantly decreased in the self-strength exercise group and the muscle energy technique group, which were the experimental groups. Spine bending was also observed to increase significantly. These findings are consistent with those of the reduction in thoracic kyphosis by applying muscle strengthening in previous studies. ${ }^{19,24}$ In the selfextension exercise group and the muscle energy technique group, the thoracic kyphosis significantly reduced, and the respiratory function significantly increased. Increased kyphosis angle causes the shortening of the pectoral muscles. In this study, kyphosis angle had a significant effect on thoracic kyphosis because self-stretching exercises and muscle energy techniques were applied to relax the pectoral muscles. ${ }^{31}$ Therefore, this study shows a link between spinal hyperflexion and respiratory function, and it can serve as a reference for the development of an exercise therapy program for patients with spinal hypertropia. The limitations of the study are that the small number of subjects, subjects' age limited to younger age groups, and short duration of the intervention. Future studies should include a larger number of subjects with more age ranges.

\section{CONCLUSIONS}

This study investigated the effects of self-extension and muscle energy techniques on the kyphosis angle and respiratory function of 30 subjects ( 24 males, 6 females) with excessive spine curvature. The results showed that selfextension exercise significantly increased the kyphosis angle, effort disposal, and $1 \mathrm{~s}$ effort exhalation but did not affect the maximum exhalation speed. The muscle energy technique 
showed a significant decrease in spine deflection and effort waste but did not affect the $1 \mathrm{~s}$ effort expiratory volume and maximum expiratory speed. Thus, the self-extension exercise and muscle energy technique reduced the spine curvature and positively affected the pulmonary function of effortful waste and $1 \mathrm{~s}$ effort. This study can be used as a reference for the development of respiratory and exercise therapy programs for patients with spinal deformity.

\section{Key Points}

Question Changes in the pulmonary function of subjects with thoracic kyphosis according to the two stretching exercises of the pectoralis minor muscle.

Findings The self-stretching exercise reduced the kyphosis and significantly increased the FVC and FEV1. The muscle energy technique reduced the kyphosis and significantly increased the FVC.

Meaning The muscle energy technique and self-stretching exercise can be applied as effective treatment programs for improving the pulmonary function of kyphosis patients.

\section{Article information}

Conflict of Interest Disclosures: None.

Funding/Support: None.

Acknowledgment: None.

Ethic Approval: None.

\section{REFERENCES}

1. Jiang H, Raso JV, Moreau MJ, et al. Quantitative morphology of the lateral ligaments of the spine. Assessment of their importance in maintaining lateral stability. Spine (Phila Pa 1976). 1994;19(23):2676-2682.

2. Edmondston SJ1, Singer KP. Thoracic spine: anatomical and biomechanical considerations for manual therapy. Man Ther. 1997;2(3):132-143.

3. Panjabi MM1, Takata K, Goel V, et al. Thoracic human vertebrae. Quantitative three-dimensional anatomy. Spine (Phila Pa 1976). 1991;16(8):888-901.

4. Fon GT, Pitt MJ, Thies AC Jr. Thoracic kyphosis: range in normal subjects. AJR Am J Roentgenol. 1980;134(5): 979983.

5. Nishiwaki Y, Kikuchi Y, Araya K, et al. Association of thoracic kyphosis with subject poor health, functional activity and blood pressure in the community-dwelling elderly. Environ Health Prev Med. 2007;12(6):246-350.

6. Kim SY, Jang HJ. Clinical importance and measurement in thoracic kyphosis. Korean Academy of Orthopedic
Manual Physiacl Therapy. 2012;18(1):1-10.

7. Kebaetse M1, McClure P, Pratt NA. Thoracic position effect on shoulder range of motion, strength and three dimensional scapular kinematics. Arch Phys Med Rehabil. 1999;80(8):945-950.

8. Kendall FP, Kendall EM, Provance PG. Muscles testing and function with posture and pain. Lippincott: Williams \& Wilkins; 2005.

9. Kim SY, Song JE, Jang HE. A comparison of the effects of self-mobilization and strengthening exercise of the thoracic region in young adults with thoracic hyperkyphosis. Korea Academy of Orthopedic Manual Therapy. 2013;19(2):11-18.

10. Lehnert-Schroth C. Three-dimensional treatment for scoliosis. The schroth orthopedic breathing system. A physiotherapeutic method to improve deformities of the spine. Germany: Books on Demand; 2007.

11. Hahn MS, Lee DY. Pulmonary function in kyphosis and scoliosis of the spine. J Musculoskelet Surg. 1971;6(4): 361-364.

12. Katzman WB1, Wanek L, Shepherd JA, et al. Age-related hyperkyphosis: its causes, consequences, and management. J Orthop Sports Phys Ther. 2010; 40(6): 352-360.

13. Harman K, Hubley-Kozey C, Butler H. Effectiveness of an exercise program to improve forward head posture in normal adults: a randomized, controlled 10-week trial. $J$ Man Manip Ther. 2005;13(3):163-176.

14. Teschke K1, Trask C, Johnson P, et al. Measuring posture for epidemiology: comparing inclinometry, observations and self-reports. Ergonomics. 2009;52(9): 1067-1078.

15. Clapis PA1, Davis SM, Davis RO. Reliability of inclinometer and goniometric measurements of hip extension flexibility using the modified Thomas test. Physiother Theory Pract. 2008;24(2):135-141.

16. Finkelstein SM1, Lindgren B, Prasad B, et al. Reliability and validity of spirometry measurements in a paperless home monitoring diary program for lung transplantation. Heart Lung. 1993;22(6):523-533.

17. Miller MR, Hankinson J, Brusasco V. et al. Standardisation of spirometry. Eur Respir. 2005;26(2):319-338.

18. Jo MR, Kim NS, Jung JH. the effects of respiratory muscle training on respiratory function, respiratory muscle strength, and cough capacity in stroke patients. $J$ Korean Soc Phys Med. 2014;9(4):399-405.

19. Rosa DP, Borstad JD, Pogetti LS, et al. Effects of a stretching protocol for the pectoralis minor on muscle lengh, function, and scapular kinematics in individuals with and without shoulder pain. J Hand Ther. 2017; 30(1):20-29.

20. Thomas H. Massage for orthopedic conditions by Thomas 
Hendrickson. Lippincott: Williams \& Wilkins Co; 1987.

21. Kim MJ. Effects of the medex exercise therapy program on cervical muscle strength and pain. Master's thesis. YongIn University; 2000.

22. Edmondston SJ. Clinical biomechanics of the thoracic spine including the ribcage. Grieve's modern manual therapy: the vertebral column. Edinburgh: Elsevier Churchill Livingstone; 2005.

23. Lee LJ, Coppieters MW, Hodges PW. Differential activation of the thoracic multifidus and longissimus thoracis during trunk rotation. Spine (Phila Pa 1976). 2005;30(8):870-876.

24. Singer KP, Giles LG. Manual therapy considerations at the thoracolumbar junction: an anatomical and functional perspective. J Manipulative Physiol Ther. 1990; 13(2): 83-88.

25. Ryan SD, Fried LP. The impact of kyphosis on daily functioning. J Am Geriatr Soc. 1997;45(12):1497-1486.

26. Takahashi T1, Ishida K, Hirose D, et al. Trunk deformity is associated with a reduction in outdoor activities of daily living and life satisfaction in community-dwelling older people. Osteoporos Int. 2005;16(3):273-279.

27. Kado DM, Browner WS, Palermo L, et al. Vertebral fractures and mortality in older women: a prospective study. Study of osteoporotic fractures research group. Arch Intern Med. 1999;14;159(11):1215-1220.

28. Freyschuss U, Nilsonne U, Lundgren KD. Idiopathic scoliosis in old age. Acta Medica Scandinavia. Acta Med Scand. 1968;184(5):365-372.

29. Lee K1, Swanson N, Sauter S, et al. A review of physical exercise recommended for VDT operators. Appl Ergon. 1992;23(6):387-408.

30. Voss DE, Ionta MK, Myers BJ. Proprioceptive neuromuscular facilitation. Philadelphia: Williams \& Wilkins; 1985.

31. Moon HH. Kim JH, Park YJ. The effect of improvement of the spinal curvature, cervical pain and neck disability index for chronic neck patients with kyphosis. J Sport Leis Stud. 2014;57(2):925-933. 